\title{
Laparoscopic Cholecystectomy under Spinal Anaesthesia: A Prospective Study
}

\author{
Dr. Manish K. Singh* and Dr. Alok Kumar ** \\ *Associate Professor of Surgery, Major S.D. Singh Medical College and Hospital \\ **Assistant Professor of Surgery, Narayan Medical College and Hospital
}

\begin{abstract}
Nowadays laparoscopic cholecystectomy ( LC) is the gold standard treatment for chronic cholecystitis with cholelithiasis.. General anesthesia with positive pressure ventilation is the preferred mode of anesthesia in this technique. There are limited data about LC under spinal anesthesia. This study was designed to evaluate LC under spinal anesthesia for uncomplicated chronic cholecystitis with cholelithiasis .

In this prospective study, 335consecutive patients of ASA grade I or II, with a mean age of 32.5 years and mean BMI of $21.35 \mathrm{~kg} / \mathrm{m} 2$, suffering from chronic cholecystitis with cholelithiasis, were included. All patients were informed about spinal anesthesia in detail. The patients were informed about the risk of conversion to general anesthesia, and all patients provided informed consent. Standard laparoscopic technique was applied to all patients. Simple questionnaire forms were developed for patients to provide comments about the operation. All the patients received ondansetron, diazepam, and pentazocine as premedication. Monitored anesthesia care was given.

The operation was completed laparoscopically on 329 patients, while 6 patients were converted for open technique. None of the patients developed cardiopulmonary problems other than transient hypotension.. None of the patients required conversion to general anaesthesia.One hundred seventy patients developed mild right shoulder. Intravenous tramadol hudrochloride $(100 \mathrm{mg})$ was needed in 113 patients due to severe right shoulder pain. Twenty five patients complained about postural headache in postoperative period. Mean operative time was 25.35 minutes. In post operative period median pain score at $4 \mathrm{hr}$ was 1.5 (range, 0-5), at 8 hr it was 1 (range, 0-6), and at $24 \mathrm{hr}$ it was 1 (range, 0-4). No one patient developed wound infection or any other complication. All 329 patients were discharged after $24 \mathrm{hr}$. All of the patients' answers to the questions regarding the comfort of operation were " well" at the 1-month postoperative evaluation.Laparoscopic cholecystectomy with low-pressure CO2 pneumoperitoneum can be successfully and safely performed under spinal anesthesia. Furthermore, it seems that spinal anesthesia is associated with minimal postoperative pain and at least an equally good recovery as with general anesthesia.
\end{abstract}

Keywords: Laparoscopic cholecystectomy, spinal anesthesia, monitored anesthesia care

\section{Introduction}

Endotracheal general anaesthesia (GA) is the anaesthetic technique of choice for laparoscopic cholecystectomy (LC). Regional anaesthesia too (spinal/epidural/combined spinal epidural) has been reported as a sole technique for performing LC as an alternative to GA for . Initially it was reported only for cases who were otherwise high risk candidates for general anaesthesia,[1,2] more recently it has been reported as a routine technique for otherwise healthy patients also.[3,4] It was thought that laparoscopy cholecystectomy necessitates endotracheal intubation. This was to prevent aspiration, abdominal discomfort and hypercarbia which was expected secondary to induction of $\mathrm{CO} 2$ pneumoperitoneum.[5] Recent studies demonstrate that laparoscopic cholecystectomy with low-pressure $\mathrm{CO} 2$ pneumoperitoneum can indeed be safely performed under spinal anaesthesia (SA).[6] In spite of the emerging evidence that laparoscopic cholecystectomy can be performed safely under regional anaesthesia, it has not gained widespread acceptance. The aim of our study is to evaluate the feasibility and safety of spinal anaesthesia for laparoscopic cholecystectomy. As a pilot study we included a selected group of patients with low body mass index (BMI) and uncomplicated chronic cholecystitis with cholelithiasis.

\section{Material And Methods}

We conducted a prospective study over a fourty-month period where LC was performed on 335 patients (267 females and 68 males) of ASA grade I or II, who presented with chronic cholecystitis with cholelithiasis . Mean age of patients was 32.5 years ranging from 28 to 55 years, with a mean BMI of 21.35 $\mathrm{kg} / \mathrm{m} 2$ ranging from 19.18 to $26.25 \mathrm{~kg} / \mathrm{m} 2$. Inclusion criteria included $-\mathrm{h} / \mathrm{o}$ recurrent pain in the right hypochondrium without tenderness in the right hypochondrium or patient for elective laparoscopic cholecystectomy and more than 25 years. All the patients had a plain abdominal radiograph, routine blood tests, and a sonographic examination. All patients were informed about spinal anesthesia in detail. The patients were 
informed about the risk of conversion to general anesthesia, and all patients provided informed consent. Simple questionnaire forms were developed for patients to provide comments about the operation.

Preoperatively about $500 \mathrm{ml}$ of Ringer's lactate solution was infused in all patients except patients with hypertension. Intravenous antibiotic (ceftriaxone) was given. Standard spinal puncture with $26 \mathrm{G}$ spinal needle was done between L1 and L2 spaces at right lateral position. Only $3.5 \mathrm{ml}$ of $0.5 \%$ bupivacaine heavy was given. Patient was kept in right lateral position for about $30 \mathrm{sec}$ and then turned to supine with head end of the table tilted down $10-15^{\circ}$ with a pillow under the head. Pantoprazole $(20 \mathrm{mg})$, Ondansetron $(100 \mu \mathrm{g} / \mathrm{kg}$.), diazepam $(200 \mu \mathrm{g} / \mathrm{kg}$.), and pentazocine $(500 \mu \mathrm{g} / \mathrm{kg})$ were used as premedication. Monitored anesthesia care (MAC) was given. All patients were monitored for blood pressure (non-invasive), heart rate, electrocardiogram, and oxygen saturation by pulse oximetry. The pneumoperitoneum was created using carbon-di-oxide and the pressure was kept at $9-10 \mathrm{mmHg}$. The table was kept in the revese Trendelenburg position with $15^{\circ}$ left tilt. Standard four port technique was applied for Laparoscopic cholecystectomy. The patients were started orally after $4 \mathrm{hrs}$ of operation and solid food on the next day. Patients were called for a revisit after a week for follow-up. Operative time, conversion, complications , post operative pain ,hospital stay \&cosmetic results were analyzed.

\section{Results}

The operation was completed laparoscopically on 329 patients, while 6 patients were converted for open technique due to dense adhesion. None of the patients developed cardiopulmonary problems other than transient hypotension.. None of the patients required conversion to general anaesthesia.One hundred seventy patients developed mild right shoulder. Intravenous tramadol hudrochloride (100 mg) was needed in 113 patients due to severe right shoulder pain. Twenty five patients complained about postural headache in postoperative period. Mean operative time was 25.35 minutes. In post operative period median pain score at 4 hr was 1.5 (range, 0-5), at $8 \mathrm{hr}$ it was 1 (range, 0-6), and at $24 \mathrm{hr}$ it was 1 (range, 0-4). No one patient developed wound infection or any other complication. All 329 patients were discharged after 24 hr. All of the patients' answers to the questions regarding the comfort of operation were " well" at the 1-month postoperative evaluation.. Almost all patients satisfied with their cosmetic results. All of the patients' answers to the questions regarding the comfort of operation were " well" at the 1-month postoperative evaluation.

\section{Discussion}

Though regional anaesthesia for laparoscopic cholecystectomy has been shown to be safe, and associated with better post operative pain control, it has not become the anaesthesia procedure of choice. There may be multiple reasons for this. It is assumed that pneumoperitoneum induces rise in intra-abdominal pressure. This may result in regurgitation of gastric content thus necessitating the use of endotracheal intubation to prevent aspiration in such an eventuality.[1,2] The increased intra-abdominal pressure during pneumoperitoneum, together with the head-up tilt used in upper abdominal laparoscopies, is believed to decrease venous return to the heart.[7,8] Spinal anaesthesia itself induces peripheral vasodilatation. Hence, there is a fear that laparoscopic procedure done under spinal anaesthesia may result in hypotension. Indeed, effects of $\mathrm{CO}_{2}$ pneumoperitoneum on intra-operative haemodynamics under SA is not a well studied scenario. In our study, we notice that liberal pre-anaesthetic hydration prevents occurrence of hypotension. Sinha et al.[4] noted an incidence of hypotension as $20.5 \%$ in their series. While we did have transient hypotension in some cases only and corrected with saline infusion .

The negative effects of the pneumoperitoneum with $\mathrm{CO}_{2}$ on the respiratory function have been widely investigated. Initially, absorption of $\mathrm{CO}_{2}$ increases its elimination in the expired air, in the arterial and venous blood.[9,10] This carboxemia induces metabolic and respiratory acidosis which decreases arterial and mixed venous $\mathrm{pH}$ and arterial $\mathrm{pO}_{2}$. [11,12] In our study we noticed that the $\mathrm{SpO}_{2}$ remained within normal limits for the patients undergoing LC under SA. Retention of $\mathrm{CO}_{2}$ and hypoxemia were not observed in the spinal anaesthesia group during the procedure. This experience is similar to that noted by other study $[9,10]$ and confirms safety of creating $\mathrm{CO}_{2}$ pneumoperitoneum under SA. None of the patients of LC under SA were converted to GA. This is similar to experience of other authors too where the incidence of conversion from SA to GA was noted to range from nil to $2.8 \%$. $[3,4,6]$

Incidence of referred pain to the right shoulder, while doing LC under regional anaesthesia, has been described as ranging from $25 \%-43 \%$.[3,4,6,13] Referred pain to right shoulder is a well described phenomena and is thought to occur due to irritation of subdiaphgramatic surface by the $\mathrm{CO}_{2}$ pneumoperitoneum.[14] The incidence of the same in our study was $113 / 329$ cases (34\%). All of these were managed by Intravenous tramadol hydrochloride and none required conversion to GA. This is helped by the fact we used low pressure pneumoperitoneum $(10 \mathrm{mmHg})$ during the surgical procedure. While standard LC entails a pneumoperitoneum at $12-16 \mathrm{mmHg}$, pneumoperitoneum pressure below $10 \mathrm{mmHg}$ has been shown to be associated with lesser abdominal/shoulder pain.[15] 
Low pressure pneumoperitoneum in our cases added to technical complexity of the dissection process. The surgeon had to be slower and gentler in tissue dissection. Additionally, on occasions, it became necessary to interrupt the procedure when the patient complained of discomfort and then the anaesthesiologist had to intervene with additional medication. This explains the fact that the pneumoperitoneum time and correspondingly the surgery time was more in the SA group. Other studies[16,17] too have documented the technical difficulty faced by the surgeon when operating in limited field permitted by low pressure pneumoperitoneum. The significant advantage of this is in terms of reduced post-operative pain, less use of analgesics, preservation of pulmonary function, and reduced hospital stay.

The post-operative recovery of patients was normal in all patients of. It is described that SA is associated with lower frequency of serious peri-operative morbidities and an improved outcome when compared to GA.[18,19] . Bessa et al.,[20] in a study confirm that LC done under SA results in significantly less early post-operative pain, compared to that performed under general anaesthesia.

It may be argued that GA permits true "day care" anaesthesia with the patient being discharged to home the same evening while SA would entail an overnight stay. Based on own experience, we would agree that GA would permit "day care LC" even in healthcare setups of developing countries.[21] But it is imperative to understand that true day care anaesthesia on an universal basis is less likely to be feasible in a developing country like ours where there are inherent limitation of availability of reliable transport, facility for home nursing, and the fact that majority of the cases reporting to our urban hospitals do so from far off rural areas. Hence, most patients have to be admitted at least for an overnight period whether they are done under GA or SA. Though the surgery done under spinal anaesthesia was technically more demanding and resulted in longer operating time, there were no late complications noted in our series which would allay the fear that technical difficulty in surgery would result in compromise in patient safety. However, it would be pertinent to mention that this endeavour should be undertaken by surgeons with adequate skills and experience in laparoscopic surgery.

This study confirms the feasibility and safety of spinal anaesthesia as the sole anaesthesia technique for conduct of elective laparoscopic cholecystectomy (LC). The patient outcomes are similar to that observed if the surgery is done under general anaesthesia. This study did not include a cost analysis, but other studies[22] indicate that laparoscopic cholecystectomy under SA is more cost effective than under GA. This makes SA an attractive option as the anaesthesia of choice especially in developing countries.

\section{Conclusion}

Laparoscopic cholecystectomy with low-pressure CO2 pneumoperitoneum can be successfully and safely performed under spinal anesthesia. Furthermore, it seems that spinal anesthesia is associated with minimal postoperative pain and at least an equally good recovery as with general anesthesia.

\section{References}

[1]. Pursnani KG, Bazza Y, Calleja M, Mughal MM. Laparoscopic cholecystectomy under epidural anaesthesia in patients with chronic respiratory disease. Surg Endosc. 1998;12:1082-4. [PubMed]

[2]. Gramatica L, Jr, Brasesco OE, Luna MA, Martinessi V, Panebianco G, Labaque F, et al. Laparoscopic cholecystectomy performed under regional anaesthesia in patients with obstructive pulmonary disease. Surg Endosc. 2002;16:472-5. [PubMed]

[3]. Tzovaras G, Fafoulakis F, Pratsas K, Georgopoulou S, Stamatiou G, Hatzitheofilou C. Laparoscopic cholecystectomy under spinal anaesthesia: A pilot study. Surg Endosc. 2006;20:580-2. [PubMed]

[4]. Sinha R, Gurwara AK, Gupta SC. Laparoscopic cholecystectomy under spinal anaesthesia: A study of 3492 patients. J Laparoendosc Adv Surg Tech A. 2009;19:323-7. [PubMed]

[5]. Sharp JR, Pierson WP, Brady CE. Comparison of CO2 and N2O-induced discomfort during peritoneoscopy under local anaesthesia. Gastroenterology. 1982;82:453-6. [PubMed]

[6]. Gautam B. Spinal anaesthesia for laparoscopic cholecystectomy: A feasibility and safety study.Kathmandu Univ Med J (KUMJ) 2009;7:360-8. [PubMed]

[7]. Gutt CN, Oniu T, Mehrabi A, Schemmer P, Kashfi A, Kraus T, et al. Circulatory and respiratory complications of carbon dioxide insufflation. Dig Surg. 2004;21:95-105. [PubMed]

[8]. Hirvonen EA, Poikolainen EO, Pääkkönen ME, Nuutinen LS. The adverse hemodynamic effects of anesthesia, head-up tilt, and carbon dioxide pneumoperitoneum during laparoscopic cholecystectomy. Surg Endosc. 2004;14:272-7. [PubMed]

[9]. Ali Y, Elmasry MN, Negmi H, Al Ouffi H, Fahad B, Rahman SA. The feasibility of spinal anesthesia with sedation for laparoscopic general abdominal procedures in moderate risk patients. Middle East J Anesthesiol. 2008;19:1027-39. [PubMed]

[10]. Imbelloni LE, Fornasari M, Fialho JC, Sant'Anna R, Cordeiro JA. General anesthesia versus spinal anesthesia for laparoscopic cholecystectomy. Rev Bras Anestesiol. 2010;60:217-27. [PubMed]

[11]. Gebhardt H, Bautz A, Ross M, Loose D, Wulf H, Schaube H. Pathophysiological and clinical aspects of the CO2 pneumoperitoneum (CO2-PP) Surg Endosc. 1997;11:864-7. [PubMed]

[12]. Gándara V, de Vega DS, Escriú N, Zorrilla IG. Acid-base balance alterations in laparoscopic cholecystectomy. Surg Endosc. 1997;11:707-10. [PubMed]

[13]. van Zundert AA, Stultiens G, Jakimowicz JJ, Peek D, van der Ham WG, Korsten HH, et al. Laparoscopic cholecystectomy under segmental thoracic spinal anaesthesia: A feasibility study. Br J Anaesth.2007;98:682-6. [PubMed]

[14]. Sarli L, Costi R, Sansebastiano G, Trivelli M, Roncoroni L. Prospective randomized trial of low-pressure pneumoperitoneum for reduction of shoulder-tip pain following laparoscopy. Br J Surg. 2000;87:1161-5.[PubMed] 
[15]. Gurusamy KS, Samraj K, Davidson BR. Low pressure versus standard pressure pneumoperitoneum in laparoscopic cholecystectomy. Cochrane Database Syst Rev. 2009;15:CD006930. [PubMed]

[16]. Chok KS, Yuen WK, Lau H, Fan ST. Prospective randomized trial on low-pressure versus standard-pressure pneumoperitoneum in outpatient laparoscopic cholecystectomy. Surg Laparosc Endosc Percutan Tech. 2006;16:383-6. [PubMed]

[17]. Joshipura VP, Haribhakti SP, Patel NR, Naik RP, Soni HN, Patel B, et al. A prospective randomized, controlled study comparing low pressure versus high pressure pneumoperitoneum during laparoscopic cholecystectomy. Surg Laparosc Endosc Percutan Tech. 2009;19:234-40. [PubMed]

[18]. Standl T, Eckert S, Schulteam Esch J. Postoperative complaints after spinal and thiopentone-isofluraneanesthesia in patients undergoing orthopaedic surgery. Spinal versus general anaesthesia. Acta Anaesthesiol Scand. 1996;40:222-6. [PubMed]

[19]. Rodgers A, Walker N, Schug S, McKee A, Kehlet H, van Zundert A, et al. Reduction of postoperative morbidity and mortality with epidural or spinal anesthesia: Results from overview of randomized trials. BMJ.2000;321:1493. [PMC free article] [PubMed]

[20]. Bessa SS, El-Sayes IA, El-Saiedi MK, Abdel-Baki NA, Abdel-Maksoud MM. Laparoscopic cholecystectomy under spinal versus general anesthesia: A prospective, randomized study. J Laparoendosc Adv Surg Tech A. 2010;20:515-20. [PubMed]

[21]. Chauhan A, Mehrotra M, Bhatia PK, Baj B, Gupta AK. Daycare laparoscopic cholecystectomy: A feasibility study in a public health service hospital in a developing country. World J Surg. 2006;30:1-6.[PubMed]

[22]. Liu X, Wei C, Wang Z, Wang H. Different anesthesia methods for laparoscopic cholecystectomy.Anaesthesist. 2011;60:723PubMed] 